\title{
Níveis de Energia e Peletização no Desempenho e Rendimento de Carcaça de Frangos de Corte com Oferta Alimentar Equalizada
}

\author{
Cibele Meinerz ${ }^{1}$, Andréa Machado Leal Ribeiro², Antônio Mario Penz Jr²., Alexandre de Mello Kessler²
}

\begin{abstract}
RESUMO - Foi realizado um experimento para avaliar os efeitos dos níveis de energia (2900-BE- e 3200-AE- kcal EM/kg), da forma física da ração (farelada-RF, peletizada em matriz de $2 \mathrm{~mm}-\mathrm{RP} 2$ e de $4 \mathrm{~mm}-\mathrm{RP} 4$ ) e da uniformização de consumo, através da restrição (Rs) alimentar quantitativa baseada no consumo de ração (CR) obtido de rações oferecidas ad libitum (Ad)/RF/AE, sobre o desempenho e o rendimento de carcaça de frangos de corte, machos, dos 21 aos 42 dias de idade. Foram empregados oito tratamentos, cinco repetições, 12 aves/repetição. Foram oferecidos somente peletes íntegros das RP. Nestas condições não houve diferença no desempenho e nos parâmetros de carcaça entre RP2 e RP4, embora a RP2/BE tenha tido menor porcentagem de finos (12\%) do que a RP4/BE (27\%). A equalização do consumo entre RF/AE e RP2+RP4/BE resultou em GP (ganho de peso) similares ( $\mathrm{P}>0,05)$, porém melhor conversão calórica $(\mathrm{CC})(\mathrm{P}<0,06)$ para $\mathrm{RF} / \mathrm{AE}$. Entre as dietas $\mathrm{BE}$, apesar do $\mathrm{CR}$ ter sido significativamente menor nas $\mathrm{RP} / \mathrm{Rs}(\mathrm{P}<0,001)$ comparado com RF/Ad, não houve diferenças para GP, CA (conversão alimentar) e CC. Comparando energia e forma física, as dietas RP/BE/Ad proporcionaram maior $\mathrm{CR}$, GP, maior porcentagem de gordura abdominal e melhor $\mathrm{CC}$, mas pior $\mathrm{CA}$, quando comparadas com $\mathrm{RF} / \mathrm{AE} / \mathrm{Ad}$. Também tiveram maior retorno econômico do que RF/Ad, em ambos os níveis de energia. A peletização parece evidenciar-se mais vantajosa com rações de baixa energia.
\end{abstract}

Palavras-chave: desempenho, energia, frangos de corte, peletização

\section{Energy Level and Pelleting on Performance and Carcass Yield of Pair-Fed Broilers}

\begin{abstract}
An experiment was conducted to evaluate the effect of energy levels (2900-LE and 3200-HE- kcal ME/kg), physical form of the diet (mash-M and pellet with $2 \mathrm{~mm}-\mathrm{P} 2$ and $4 \mathrm{~mm}-\mathrm{P} 4$ ) and pair feeding (Pf), by feed restriction based in Ad libitum (Ad)/ $\mathrm{M} / \mathrm{HE}$ diets, on male broilers performance and carcass yield, from 21 to 42 days of age. There were 8 treatments, 5 replicates, 12 birds/ replicate. In the P diets, only whole pellets were offered. At these conditions, there were no differences on performance and carcass parameters between P2 and P4 diets, although P2/LE showed less fines (12\%) than P4/LE (27\%). Pair-feeding M/HE and P2+P4/LE resulted in similar weight gain $(\mathrm{WG})(\mathrm{P}<0,05)$, but better caloric efficiency $(\mathrm{CE})(\mathrm{P}<0,06)$ for $\mathrm{M} / \mathrm{HE}$. Among LE diets, although FI was lower in $\mathrm{P} / \mathrm{Pf}(<0.001)$ when compared with $\mathrm{M} / \mathrm{Ad}$, there was no differences for WG, FE (feed efficiency) and CE. Comparing energy and diet form, the P/LE/Ad diets gave a greater FI, WG, abdominal fat and better CE, but worse FE compared with $\mathrm{M} / \mathrm{HE} / \mathrm{Ad}$. Also had more economic return compared with M/Ad, in both energy levels. The pelleting process seems to be more profitable with low energy diets.
\end{abstract}

Key Words: broilers, energy, pellets, performance

\section{Introdução}

É sabido que a peletização aumenta o custo da ração em torno de $2 \%$, sendo um processo de grande demanda de energia e de capital em uma fábrica de ração. Ele pode influenciar o rendimento da fábrica de rações principalmente se esta não for dimensionada para comportá-lo, e possuir uma produção acima de sua capacidade, o que normalmente acontece na maioria das empresas avícolas brasileiras. Por outro lado, um dos resultados da peletização é o aumento do consumo de ração pelos frangos de corte e, conseqüentemente, maior ganho de peso (CALET,
1965). Afora isso, JENSEN et al (1962) e NIR et al. (1994) afirmam que o principal efeito da peletização é a redução na energia de mantença, aumentando a energia líquida de produção; SLINGER (1972) sugere que a peletização favorece a destruição térmica de fatores tóxicos que prejudicam a utilização da gordura e/ou proteína dos alimentos, aumentando a energia metabolizável da dieta. KLEIN (1996), LECZNIESKI (1997) e MAIORKA (1998) verificaram que a peletização favorece o consumo de ração e a eficiência de retenção da energia metabolizável aparente, quando comparada a dietas fareladas. Porém, verificaram que frangos de corte consumindo rações

\footnotetext{
${ }^{1}$ Aluna de Mestrado do curso de Pós-graduação em Zootecnia da UFRGS- Financiado pela FAURGS

2 Professores do Departamento de Zootecnia da UFRGS. E.mail: aribeiro@vortex.ufrgs.br; ampenz@conex.com..br; akessler@vortex.ufrgs.br
} 
peletizadas apresentam maior quantidade de gordura, tanto sob a forma de gordura abdominal quanto em relação à gordura total da carcaça e vísceras. LECZNIESKI (1997) e MAIORKA (1998) sugerem que o uso de dietas diluídas energeticamente, mas peletizadas, possam corrigir o excesso de gordura na carcaça, pela redução final no consumo de energia.

O tamanho e a firmeza das partículas alimentares afetam os sentidos que acompanham o comportamento da ingestão de alimentos (GOTTSCHALDT E LAUSMANN, 1974). Assim, o tamanho de pelete também pode exercer influência sobre o desempenho, na medida em que peletes menores tendem a ser mais resistentes. Segundo NILIPOUR (1994), peletes de má qualidade (com alto teor de finos) podem ser responsáveis por índices de conversão alimentar até $13 \%$ piores quando comparados com rações peletizadas de boa qualidade.

As exigências energéticas das aves são responsáveis por $70 \%$ do custo da ração de frangos (SKINNER et al., 1992). Desse modo, este último é altamente influenciado pelos níveis de energia da ração. Esta, quando consumida além das necessidades para manutenção e crescimento de tecido muscular das aves, é depositada como gordura corporal, o que representa um produto de menor aceitabilidade em função da preocupação do mercado em consumir baixo conteúdo de gordura. Dessa forma, o uso de dietas com baixa energia tem sido sugerido como forma não só de reduzir custos, mas também de produzir uma carcaça de maior qualidade, com menor teor de gordura.

Em função do que foi colocado, este trabalho tem por objetivo observar o efeito da peletização numa condição de consumo pareado com rações fareladas, em dietas com distintos níveis de energia e entre diferentes tamanhos de peletes, no que diz respeito ao ganho de peso (GP), consumo e ração (CR), conversão alimentar (CA), conversão calórica (CC) e rendimento de carcaça de frangos de corte.

\section{Material e Métodos}

Foram usados 480 frangos de corte Ross, criados em baterias, de 19 a 42 dias de idade, nas instalações do Laboratório de Ensino Zootécnico da Faculdade de Agronomia da UFRGS. As aves foram selecionadas de uma população maior, observando um peso médio de $545 \mathrm{~g}( \pm 5 \%)$. O período experimental foi de 21 a 42 dias. Foram comparadas dietas com diferentes níveis de energia (2900-BE x 3200-AE
$\mathrm{kcalEM} / \mathrm{kg}$ de ração), formas físicas (ração farelada$\mathrm{RF} x$ ração peletizada- $R P$ ) e diâmetros de pelete (2 mm - RP2 x $4 \mathrm{~mm}$ - RP4), com fornecimento ad libitum (Ad) ou restrito (Rs), distribuídas em delineamento inteiramente casualizado, com oito tratamentos (cinco repetições, 12 aves por unidade experimental), conforme descrição abaixo:

\begin{tabular}{|c|c|c|c|c|c|c|}
\hline \multirow{2}{*}{$\begin{array}{l}\text { Energia } \\
\text { Energy } \\
(\mathrm{kcalEM} / \mathrm{kg})\end{array}$} & \multicolumn{2}{|c|}{$\begin{array}{l}\text { Farelada } \\
\text { Mash }\end{array}$} & \multicolumn{4}{|c|}{$\begin{array}{c}\text { Peletizada } \\
\text { Pellet }\end{array}$} \\
\hline & & & $\begin{array}{c}\text { Ad } \\
2 \mathrm{~mm}\end{array}$ & $\begin{array}{c}\mathrm{R} \\
4 \mathrm{~mm}\end{array}$ & $\begin{array}{c}\mathrm{Ad} \\
2 \mathrm{~mm}\end{array}$ & $\begin{array}{c}\mathrm{R} \\
4 \mathrm{~mm} \\
\end{array}$ \\
\hline 3200 & T1 & - & - & - & - & $\mathrm{T} 2$ \\
\hline 2900 & T7 & T8 & $\mathrm{T} 3$ & T5 & $\mathrm{T} 4$ & T6 \\
\hline
\end{tabular}

$\mathrm{Ad}=$ alimentação à vontade (Ad libitum)

$\mathrm{R}=$ alimentação restrita, baseada no consumo das aves do T1(Pair feed at T1 level).

2 e $4 \mathrm{~mm}=$ tamanho de pelete (pellet size).

A restrição alimentar foi empregada como metodologia de uniformização do consumo de ração, baseada na média de consumo das repetições do T1 (AE/Ad/RF), do dia anterior, fornecendo ração duas vezes ao dia. As rações experimentais, o diâmetro geométrico médio (DGM) e o desvio-padrão geométrico (DPG), segundo método de PFOST e HEADLEY (1976), das partículas das rações fareladas, encontram-se na Tabela 1. O T7 (BE/Ad/RF) foi deixado com consumo à vontade até equiparar o consumo de energia metabolizável (EM) do T1, enquanto, nos tratamentos 4 (BE/Rs/RP2), 6 $(\mathrm{BE} / \mathrm{Rs} / \mathrm{RP} 4)$ e $8(\mathrm{BE} / \mathrm{Rs} / \mathrm{RF})$, a restrição para o mesmo consumo em gramas/dia levou à uma redução na ingestão de EM. As rações peletizadas foram peneiradas em peneira de malha $3 \mathrm{~mm}$, de forma que somente peletes íntegros fossem ofertados aos animais.

O controle de consumo de ração foi feito diariamente, como também a mortalidade das aves. A pesagem das aves foi realizada semanalmente e nos valores de conversão alimentar $(\mathrm{kg} / \mathrm{kg})$ e conversão calórica (EM consumida/kg de ganho de peso, em kcal/kg)) foi considerado o peso das aves mortas. Ao término do período experimental, foram abatidas duas aves com peso corporal semelhante à média de cada unidade experimental. Foram obtidos o rendimento de carcaça (com pés e cabeça) e o peso de moela em relação ao peso total da ave (em percentual), e os valores de rendimento de perna, de peito (com pele e osso) e conteúdo de gordura abdominal, em relação ao peso de carcaça. Também foi medido o comprimento de intestino.

Rev. bras. zootec., 30(6S):2026-2032, 2001 
Tabela 1 - Composição das rações experimentais Table 1 - Composition of experimental diets

\begin{tabular}{|c|c|c|}
\hline \multirow[b]{2}{*}{ Ingredientes (\%) } & \multicolumn{2}{|c|}{$\begin{array}{l}\text { Energia metabolizáve } \\
\text { aparente (kcal/kg) } \\
\text { Apparent metabolizable } \\
\text { energy (kcal/kg) }\end{array}$} \\
\hline & 2900 & 3200 \\
\hline \multicolumn{3}{|l|}{ Ingredients } \\
\hline Milho $(8,1 \%$ PB $)$ & 58,51 & 58,51 \\
\hline \multicolumn{3}{|l|}{$\operatorname{Corn}(8.1 \% C P)$} \\
\hline Farelo de soja $(46,5 \% \mathrm{~PB})$ & 22,36 & 22,36 \\
\hline \multicolumn{3}{|l|}{ Soybean meal $(46.5 \% C P)$} \\
\hline Trigo $(14,5 \% \mathrm{~PB})$ & 2,54 & 2,54 \\
\hline \multicolumn{3}{|l|}{ Wheat $(14.5 \% C P)$} \\
\hline Glúten milho $(50,8 \% \mathrm{~PB})$ & 4,11 & 4,11 \\
\hline \multicolumn{3}{|l|}{ Corn gluten $(50.8 \% \mathrm{CP})$} \\
\hline Far. carne e ossos $(49,4 \% \mathrm{~PB})$ & 5,00 & 5,00 \\
\hline \multicolumn{3}{|l|}{ Meat and bone meal $(49.4 \% C P)$} \\
\hline Óleo de soja & 0,59 & 4,00 \\
\hline \multicolumn{3}{|l|}{ Soy oil } \\
\hline Fosfato bicálcico & 1,49 & 1,49 \\
\hline \multicolumn{3}{|l|}{ Dicalcium phosphate } \\
\hline Calcário calcítico & 1,20 & 1,20 \\
\hline \multicolumn{3}{|l|}{ Limestone } \\
\hline Sal & 0,40 & 0,40 \\
\hline \multicolumn{3}{|l|}{ Salt } \\
\hline Pré-mistura* & 0,13 & 0,13 \\
\hline \multicolumn{3}{|l|}{ Premix } \\
\hline L-Lisina & 0,15 & 0,15 \\
\hline \multicolumn{3}{|l|}{ L-lysine } \\
\hline DL-Metionina & 0,11 & 0,11 \\
\hline \multicolumn{3}{|l|}{ DL-methionine } \\
\hline Caulin & 3,41 & - \\
\hline \multicolumn{3}{|l|}{ Kaolin } \\
\hline \multicolumn{3}{|c|}{ Composição nutricional calculada } \\
\hline \multicolumn{3}{|c|}{ Calculated nutritional composition } \\
\hline $\mathrm{EM}(\mathrm{kcal} / \mathrm{kg})(M E)$ & 2900 & 3200 \\
\hline $\mathrm{PB}(\%)(C P)$ & 20,00 & 20,00 \\
\hline $\mathrm{Ca}$ & 1,00 & 1,00 \\
\hline Fósforo disp.(\%) & 0,45 & 0,45 \\
\hline \multicolumn{3}{|l|}{ Avail. $P$} \\
\hline Sódio (\%) & 0,20 & 0,20 \\
\hline \multicolumn{3}{|l|}{ Sodium } \\
\hline Colina (mg/kg) & 1323 & 1323 \\
\hline \multicolumn{3}{|l|}{ Choline } \\
\hline LIS digestível (\%) & 0,95 & 0,95 \\
\hline \multicolumn{3}{|l|}{ Dig.LYS } \\
\hline Met + cis digestível (\%) & 0,72 & 0,72 \\
\hline \multicolumn{3}{|l|}{ Dig met + cys } \\
\hline TRE digestível (\%) & 0,64 & 0,64 \\
\hline Dig.THR & & \\
\hline $\operatorname{DGM}(m)^{1}$ & 484 & 562 \\
\hline $\mathrm{DPG}^{2}$ & 2.28 & 2.21 \\
\hline $\begin{array}{l}\text { * Por kg de ração: vitamina A } 7000 \mathrm{U} \\
\mathrm{E} 20 \mathrm{Ul} \text {; vitamina } \mathrm{K}_{3} 1,5 \mathrm{mg} \text {; vitami } \\
\text { vitamina } \mathrm{B}_{6} 0,6 \mathrm{mg} \text {; vitamina } \mathrm{B}_{12} \\
\text { ácido pantotênico } 10 \mathrm{mg} \text {; biotina } \\
\text { manganês } 60 \mathrm{mg} \text {, ferro } 25 \mathrm{mg} \text {; cobre } \\
\text { iodo } 0,38 \mathrm{mg} \text {; promotores de cresc } \\
\text { flavomicina - } 0,07 \mathrm{~g} \text { ), agente anticc } \\
\text { e antioxidante (Banox }{ }^{\circledR}-0,1 \mathrm{~g} \text { ). } \\
1 \text { Diâmetro geométrico médio (Averag } \\
2 \text { Desvio- padrão geométrico (Geome }\end{array}$ & $\begin{array}{l}\text { tamina } \mathrm{D} \\
\mathrm{B}_{1} 0,6 \mathrm{mg} \\
\text { ncg; ácidd } \\
2 \mathrm{mg} \text {; áci } \\
\text {; zinco } 40 \mathrm{r} \\
\text { ento (3-NI } \\
\text { diano (mo } \\
\text { ometric dia } \\
\text { sd). }\end{array}$ & $\begin{array}{l}\text { vitamina } \\
3_{2} 5 \mathrm{mg} ; \\
23 \mathrm{mg} \\
, 25 \mathrm{mg} \\
0,18 \mathrm{mg} \\
112 \mathrm{~g} \text {; } \\
0,275 \mathrm{~g})\end{array}$ \\
\hline
\end{tabular}

Para avaliar o efeito na lucratividade, foi utilizado o Índice Bioeconômico (IBE), adaptado de Guidoni et al. (1994), em que IBE = GP - (A * CR), sendo A a relação entre o preço de $1 \mathrm{~kg}$ de ração e o preço de venda de $1 \mathrm{~kg}$ de frango inteiro. Nos custos das rações peletizadas, foi incluído o custo de repeletizar os finos até que todas as rações apresentassem a mesma percentagem de finos (12\%).

Os resultados dos tratamentos foram submetidos à análise de variância com comparações de médias pelo teste de Duncan e também por contrastes ortogonais. Foram utilizados os seguintes contrastes: tamanho de pelete, dentre as dietas de baixa energia, à vontade (T3 x T5); equalização de consumo para as dietas de alta e baixa energia (T1 x T2 e T7 x T4+T6, respectivamente); interação entre níveis de energia e forma (T1 x T3+T5); comparação das formas físicas dentro do mesmo nível de energia (T7 x T3+T5); restrição no baixo nível de energia e dieta farelada (T7 x T8). Para a análise estatística foi usado o programa computacional SAS (1985).

\section{Resultados e Discussão}

A análise de contrastes entre peletes de $2 \mathrm{~mm}$ e $4 \mathrm{~mm}$ não mostrou diferença significativa para os parâmetros de desempenho, para a maioria dos dados de carcaça e IBE (Tabelas 2 e 3). Desta forma, as demais comparações foram feitas com a média destes dois tratamentos (T3+T5) ou (T4+T6) para fornecimento Ad ou R, respectivamente. No entanto, rações de baixa energia, com pelete de $2 \mathrm{~mm}$ apresentaram menor quantidade de finos do que rações com peletes de $4 \mathrm{~mm}(12 \% \times 27 \%$, respectivamente), provavelmente em função da maior pressão da mistura de ingredientes contra a matriz da peletizadora. Porém, como neste trabalho as rações foram peneiradas, o efeito da quantidade de finos sobre o desempenho não foi avaliado. De acordo com NILIPOUR (1994), é de se supor que, se oferecida a ração integral, as aves que consumiram peletes de $2 \mathrm{~mm}$ tivessem tido melhor desempenho em função da melhor qualidade de peletes.

Com relação ao efeito da peletização, os contrastes dentro de cada nível de energia mostram que as respostas em desempenho são muito similares quando são comparados consumos semelhantes (Tabela 4). Isto significa que o maior efeito da peletização é justamente proporcionar às aves maior consumo alimentar (CALET, 1965). Isto se torna fundamental

Rev. bras. zootec., 30(6S):2026-2032, 2001 
Tabela 2 - Efeito do tamanho de pelete no desempenho e no índice bio-econômico (IBE) de aves alimentadas com rações de baixa energia, fornecidas à vontade

Table 2 - Effect of pellet size on performance and bioeconomic index in broilers fed low energy diets, offered ad libitum

\begin{tabular}{lccccc}
\hline & $\mathrm{CR}(\mathrm{g})$ & $\mathrm{GP}(\mathrm{g})$ & $\mathrm{CA}(\mathrm{g} / \mathrm{g})$ & $\mathrm{CC}(\mathrm{kcal} / \mathrm{kg})$ & $\mathrm{IBE}(\mathrm{g})$ \\
& $F I$ & $W G$ & $F E$ & $C E^{1}$ & $B E I^{2}$ \\
\hline T3-2 $\mathrm{mm}^{*}$ & 3678 & 1837 & 2,01 & 5,82 & 942 \\
$\mathrm{~T} 5-4 \mathrm{~mm}^{*}$ & 3666 & 1799 & 2,03 & 5,90 & 920 \\
$\mathrm{P}>\mathrm{F}$ & $\mathrm{NS}$ & $\mathrm{NS}$ & $\mathrm{NS}$ & $\mathrm{NS}$ & $\mathrm{NS}$ \\
\hline
\end{tabular}

* $2900 \mathrm{kcal} \mathrm{EM} / \mathrm{kg}$, à vontade (ad libitum).

${ }^{1}$ Caloric efficiency.

2 Bioeconomicindex.

sobretudo com dietas diluídas, quando a ingestão de ração é limitada pela capacidade física do trato gastrintestinal. Por outro lado, para o nível alto de energia, observa-se tendência de maior GP, CA e CC para as aves com ração farelada (contraste $\mathrm{T} 1-\mathrm{AE} /$ $\mathrm{Ad} / \mathrm{RF} \times \mathrm{T} 2$ - AE/Rs/RP4, $\mathrm{P}<0,11, \mathrm{P}<0,08$ e $\mathrm{P}<0,06$, respectivamente) (Tabela 4$)$. O tamanho de moela também mostrou diferenças, tendo sido menor para aves recebendo ração peletizada, concordando com os resultados obtidos por NIR et al. (1994) (Tabela 5). No entanto, o comprimento de intestino foi significativamente maior neste tratamento $(\mathrm{P}<0,01)$. Por fim, o IBE aponta que não haveria vantagens no uso de ração peletizada nestas condições (Tabela 4). As hipóteses de que a peletização leva à menor exigência de mantença, em função de as aves apreenderem o alimento com maior eficiência, aumentando a energia líquida de produção (NIR et al., 1994; JENSEN et al., 1962), ou a aumento da digestibilidade dos nutrientes da dieta (SCHULTZ, 1990), não se sustentam com os dados encontrados nesse trabalho.

Dentre as rações de baixa energia oferecidas à vontade e restritas (contraste T7-BE/Rs/RF x T4+T6$\mathrm{BE} / \mathrm{Rs} / \mathrm{RP}$ ), apesar de o fornecimento restrito ter sido baseado no tratamento de alto nível de energia (T1-AE/Ad/RF), o que gerou um nível de consumo menor para os tratamentos peletizado-restrito (T4+T6 comparados com T7, $\mathrm{P}<0,001$ ), para os demais parâmetros não foram observadas diferenças significativas. Os números sugerem que se tivesse havido equiparação de consumo, as rações peletizadas teriam proporcionado melhor resposta do que a farelada. Parece, portanto, haver maior benefício da peletização nas dietas com baixa energia, além do efeito sobreconsumo. Os dados desse trabalho sugerem que este efeito diminui com o aumento do conteúdo energético das rações, conforme proposto por CALET (1965) e BERTECHINI et al. (1991) e LECZNIESKI (1997).

Vários são os trabalhos que mostram que dietas peletizadas proporcionam melhor conversão alimentar (KLEIN, 1996, LECZNIESKI, 1997 e MAIORKA, 1998), bem como que a restrição alimentar melhora o aproveitamento do alimento (LEVEILLE, 1972; SU et al, 1999). No entanto, neste experimento, para as dietas de alta energia, quando os consumos foram equalizados, houve melhor $\mathrm{CA}$ e $\mathrm{CC}(\mathrm{P}<0,08$ e $\mathrm{P}<0,06$, respectivamente), para as rações fareladas, à vontade. Isto sugere a possibilidade de alguma interação entre tipo de regime de alimentação empregado $(1,2$ ou mais refeições diárias) e forma de ração, influenciando o aproveitamento de energia. A mesma observação pode ser feita nas rações de baixa energia $(\mathrm{P}<0,14$ e $\mathrm{P}<0,15$ para $\mathrm{CA}$ e $\mathrm{CC}$, respectivamente).

Tabela 3 - Efeito do tamanho de pelete no rendimento de carcaça e cortes de aves alimentadas com rações com baixa energia, fornecidas à vontade

Table 3 - Effect of pellet size on carcass yield and cuts of broilers fed low energy diets, offered ad libitum

\begin{tabular}{|c|c|c|c|c|c|c|}
\hline & $\begin{array}{l}\text { Carcaça } \\
\text { Carcass }\end{array}$ & $\begin{array}{c}\text { Perna } \\
\text { Leg }\end{array}$ & $\begin{array}{l}\text { Peito }(\%) \\
\text { Breast }\end{array}$ & $\begin{array}{l}\text { Moela } \\
\text { Guizard }\end{array}$ & $\begin{array}{c}\text { Gordura abdominal } \\
\text { Abdominal fat }\end{array}$ & $\begin{array}{c}\text { Intestino }(\mathrm{cm}) \\
\text { Intestine }\end{array}$ \\
\hline T3-2mm* & 85,8 & 26,6 & 25,0 & 1,28 & 3,22 & 197 \\
\hline T5-4mm* & 85,6 & 26,4 & 25,8 & 1,30 & 2,85 & 181 \\
\hline $\mathrm{P}>\mathrm{F}$ & NS & NS & NS & NS & NS & 0,02 \\
\hline
\end{tabular}

*2900kcal EM/kg, à vontade (ad libitum).

Rev. bras. zootec., 30(6S):2026-2032, 2001 
Tabela 4 - Efeito da equalização de consumo, da peletização e da energia da dieta no desempenho e no índice bio-econômico (IBE ) de frangos de corte

Table 4 - Effect of pair-feeding, pelleting and energy of the diet on the performance and bioeconomic index of broilers

\begin{tabular}{|c|c|c|c|c|c|c|}
\hline & $\begin{array}{l}\text { CR } \\
F I \\
(\mathrm{~g}) \\
\end{array}$ & $\begin{array}{l}\mathrm{GP} \\
W G \\
(\mathrm{~g}) \\
\end{array}$ & $\begin{array}{c}\mathrm{CA} \\
F E \\
(\mathrm{~g} / \mathrm{g}) \\
\end{array}$ & $\begin{array}{c}\mathrm{CC}^{1} \\
C E \\
(\mathrm{kcal} / \mathrm{kg}) \\
\end{array}$ & $\begin{array}{c}\text { Cons. Cal. }{ }^{2} \\
\text { Cal. intake } \\
\text { (kcal) }\end{array}$ & $\begin{array}{l}\mathrm{IBE} \\
B E I \\
(\mathrm{~g}) \\
\end{array}$ \\
\hline $\mathrm{T} 1$ & $3135^{c}$ & $1621^{b}$ & $1,93^{\mathrm{a}}$ & $6,19^{\mathrm{b}}$ & $10.031^{\mathrm{b}}$ & $855^{\mathrm{a}}$ \\
\hline $\mathrm{T} 2$ & $3112^{c}$ & $1548^{b c}$ & $2,01^{\mathrm{ab}}$ & $6,44^{\mathrm{c}}$ & $9958^{b}$ & $754^{b}$ \\
\hline $\mathrm{T} 3+\mathrm{T} 5$ & $3672^{a}$ & $1818^{a}$ & $2,02^{\mathrm{b}}$ & $5,86^{\mathrm{a}}$ & $10.632^{\mathrm{a}}$ & $931^{\mathrm{a}}$ \\
\hline T4+T6 & $3113^{c}$ & $1522^{\mathrm{cd}}$ & $2,07^{b}$ & $6,00^{\mathrm{ab}}$ & $9030^{\mathrm{d}}$ & $768^{b}$ \\
\hline $\mathrm{T} 7$ & $3307^{b}$ & $1552^{\mathrm{bc}}$ & $2,13^{\mathrm{c}}$ & $6,19^{\mathrm{b}}$ & $9590^{c}$ & $787^{\mathrm{b}}$ \\
\hline $\mathrm{T} 8$ & $3020^{\mathrm{d}}$ & $1446^{\mathrm{d}}$ & $2,09^{b c}$ & $6,06^{\mathrm{ab}}$ & $8757^{\mathrm{e}}$ & $747^{\mathrm{b}}$ \\
\hline \multirow{2}{*}{$\begin{array}{l}\text { Probabilidade } \\
\text { Probabilities }\end{array}$} & 0,0001 & 0,0001 & 0,001 & 0,0001 & 0,0001 & 0,0001 \\
\hline & \multicolumn{6}{|c|}{$\begin{array}{l}\text { Contrastes- Probabilidades } \\
\text { Contrasts-Probabilities }\end{array}$} \\
\hline $\mathrm{T} 1 \times \mathrm{T} 2$ & NS & 0,11 & 0,08 & 0,06 & NS & 0,02 \\
\hline $\mathrm{T} 7 \times \mathrm{T} 4+\mathrm{T} 6$ & 0,001 & NS & 0,03 & NS & 0,0001 & NS \\
\hline $\mathrm{T} 1 \times \mathrm{T} 3+\mathrm{T} 5$ & 0,001 & 0,001 & 0,03 & 0,01 & 0,0001 & 0,03 \\
\hline $\mathrm{T} 7 \times \mathrm{T} 3+\mathrm{T} 5$ & 0,001 & 0,001 & 0,01 & 0,01 & 0,0001 & 0,001 \\
\hline $\mathrm{T} 7 \times \mathrm{T} 8$ & 0,001 & 0,02 & NS & NS & 0,0001 & NS \\
\hline
\end{tabular}

1 Conversão calórica (caloric eficiency).

2 Consumo calórico (caloric intake).

T1:ração farelada, à vontade, $3200 \mathrm{kcal} E M / \mathrm{kg}$.

T2:ração peletizada, restrita ao nível de T1, pelete de $4 \mathrm{~mm}, 3200 \mathrm{kcal}$ EM/kg.

T3+T5: ração peletizada, à vontade, 2 e $4 \mathrm{~mm}, 2900 \mathrm{kcal} \mathrm{EM} / \mathrm{kg}$.

T4+T6: ração peletizada, restrita ao nível de T1, 2 e 4mm, $2900 \mathrm{kcal} E M / \mathrm{kg}$.

T7: ração farelada, à vontade, $2900 \mathrm{kcalEM} / \mathrm{kg}$.

T8: ração farelada, restrita ao nível de T1, 2900kcal EM/kg.

T1:meshed diet, ad libitum, $3200 \mathrm{kcal} \mathrm{ME} / \mathrm{kg}$

T2:pelleted diet, pair-feed at $T 1$ level, pellet with $4 \mathrm{~mm}, 3200 \mathrm{kcal} \mathrm{ME} / \mathrm{kg}$.

T3+T5:pelleted diet, ad libitum,pellets with 2 and $4 \mathrm{~mm}, 2900 \mathrm{kcal} \mathrm{ME} / \mathrm{kg}$.

T4+T6:pelleted diet, pair-feed at T1 level, 2 and $4 \mathrm{~mm}, 2900 \mathrm{kcal} \mathrm{ME} / \mathrm{kg}$.

T7:meshed diet, ad libitum, 2900kcal ME/kg.

T8:meshed diet, pair-fed at T1 level, 2900kcalME/k.

Nos parâmetros de carcaça, observa-se que a restrição diminuiu o rendimento de peito tanto em alta $(\mathrm{P}<0,07)$ como em baixa $(\mathrm{P}<0,08)$ energia, mas nenhum efeito foi verificado para rendimento de perna e percentagem de gordura abdominal.

Quanto à comparação entre rações de baixa energia, peletizadas (T3+T5-BE/Ad/RP) e rações de alta energia, fareladas (T1-AE/Ad/RF), oferecidas à vontade, observou-se que as aves recebendo ração peletizada de baixa energia tiveram maior CR (o que é explicado tanto pelo fator diluição da ração, como pelo efeito forma), mas também maior consumo de EM e melhor desempenho nos parâmetros avaliados, à semelhança dos resultados de LECZNIESKI (1997) e MAIORKA (1998). Quando a eficiência do uso do alimento foi analisada pela CA, verificaram-se melhores resultados para a ração farelada. No entanto, pela CC ( $\mathrm{kcal}$ consumidas/kg em ganho), nota-se que as aves recebendo dietas peletizadas de baixa energia foram mais eficientes, da mesma forma que $o$ observado por SKINNER et al (1992). Também foi verificada uma maior percentagem de gordura abdominal para as rações de baixa energia, peletizadas $(\mathrm{P}<0,001)$ (Tabela 5). Isto mostra que, porque as aves conseguem com muita eficiência regular o consumo de energia (sobretudo em dietas peletizadas), diluir a dieta não funciona como "correção" para deposição excessiva de gordura na carcaça. Outra vantagem para rações de baixa energia é a qualidade dos peletes. É sabido que a adição de gordura acima de $2 \%$ diminui a integridade dos peletes (FEED MILLING HANDBOOK, 1980). No presente experimento, as rações de alta energia, peletizadas (4 mm), tiveram $35 \%$ de finos, comparadas com $27 \%$ de finos da peletizadas (4 $\mathrm{mm}$ ), baixa energia.

Os resultados mostram que a quantidade de gordura abdominal está relacionada a consumo. Como a ração peletizada permitiu maior consumo, as aves dos tratamentos "peletizado - à vontade" tiveram maior percentagem de gordura abdominal, nos dois níveis

Rev. bras. zootec., 30(6S):2026-2032, 2001 
energéticos empregados (contraste T1-AE/Ad/RF x $\mathrm{T} 3+\mathrm{T} 5-\mathrm{BE} / \mathrm{Ad} / \mathrm{RP}$ e contraste $\mathrm{T} 7-\mathrm{BE} / \mathrm{Rs} / \mathrm{RF} \mathrm{x}$ $\mathrm{T} 3+\mathrm{T} 5)$.

Com relação à peletização dentro do mesmo nível de energia, a resposta foi positiva para rações com baixo nível energético e oferta ad libitum (contraste T7 x T3+T5), já que o desenho proposto neste experimento não contemplou a comparação dentro do alto nível de energia. No contraste acima, observa-se que as rações peletizadas proporcionaram maior consumo de ração e consequentemente maior GP e maior rendimento de carcaça e partes. Também houve diferenças significativas entre $\mathrm{CA}, \mathrm{CC}$ e $\operatorname{IBE}(\mathrm{P}<0,01$; $\mathrm{P}<0,01$ e $\mathrm{P}<0,001$, respectivamente), mostrando vantagens para as rações peletizadas (Tabela 4).

Um contraste interessante foi observado entre as rações de baixa energia e fareladas, diferindo no regime de oferta : T8-BE/Rs/RF x T7-BE/Ad/RF. No primeiro, o consumo de ração ficou abaixo da oferta diária (com sobras no cocho no final de 24 horas), sugerindo que as aves foram incapazes de consumir a quantidade de ração por unidade de tempo, mesmo que as aves do tratamento equivalente (T7) tenham consumido 200 gramas a mais $(\mathrm{P}<0,001)$. Isto indica que não foi devido à limitação no volume do trato gastrintestinal. Outros fatores, como regime de alimentação, influenciam o consumo alimentar e o aproveitamento do alimento na restrição. A oferta de alimento duas vezes ao dia, talvez, esgote a ave fisicamente, a exemplo do observado por SU et al (1999) e LEVEILLE (1972), o que pode justificar o comportamento das aves com alimentação restrita no presente experimento, que, logo após o fornecimento da ração, era de grande agitação e disputa e de ingestão de grande quantidade de alimento, apresentando papo hipertrófico após alguns minutos. A restrição alimentar também pode influenciar positivamente o aproveitamento do alimento (YU e ROBINSON, 1992). Como exemplo desta hipótese têm-se as comparações entre T8 (BE/Rs/RF) e T4+T6 $(\mathrm{BE} / \mathrm{Rs} / \mathrm{RP})$. As aves destes tratamentos não diferiram em ganho de peso ou conversão alimentar.

Comparando os tratamentos com diferentes níveis de energia, e ração farelada, oferecidos

Tabela 5 - Efeito da equalização de consumo, da peletização e da energia da dieta no rendimento de carcaça e cortes de frangos de corte

Table 5 - Effect of pair-feeding, pelleting and energy of the diet on the carcass yield and cuts

\begin{tabular}{|c|c|c|c|c|c|c|}
\hline & $\begin{array}{l}\text { Carcaça } \\
\text { Carcass }\end{array}$ & $\begin{array}{l}\text { Perna } \\
\text { Leg }\end{array}$ & $\begin{array}{c}\text { Peito } \\
\text { Breast } \\
(\%)\end{array}$ & $\begin{array}{l}\text { Moela } \\
\text { Guizard }\end{array}$ & $\begin{array}{l}\text { Gordura abdominal } \\
\text { Abdominal fat }\end{array}$ & $\begin{array}{c}\text { Intestino }(\mathrm{m}) \\
\text { Intestine }\end{array}$ \\
\hline $\mathrm{T} 1$ & 84,5 & 26,3 & $25,4^{\mathrm{ab}}$ & $1,64^{\mathrm{a}}$ & $2,36^{\mathrm{bc}}$ & $1,77^{\mathrm{bc}}$ \\
\hline $\mathrm{T} 2$ & 85,5 & 26,3 & $24,3^{\mathrm{b}}$ & $1,37^{\mathrm{b}}$ & $2,83^{\mathrm{ab}}$ & $1,96^{\mathrm{a}}$ \\
\hline $\mathrm{T} 3+\mathrm{T} 5$ & 85,7 & 26,5 & $25,4^{\mathrm{ab}}$ & $1,29^{\mathrm{b}}$ & $3,03^{\mathrm{a}}$ & $1,89^{\mathrm{ab}}$ \\
\hline $\mathrm{T} 4+\mathrm{T} 6$ & 84,4 & 26,5 & $25,3^{\mathrm{ab}}$ & $1,49^{a b}$ & $2,41^{a b c}$ & $1,80^{\mathrm{bc}}$ \\
\hline $\mathrm{T} 7$ & 85,3 & 26,4 & $26,2^{\mathrm{a}}$ & $1,62^{\mathrm{a}}$ & $2,16^{\mathrm{c}}$ & $1,74^{\mathrm{c}}$ \\
\hline T8 & 84,9 & 26,2 & $26,3^{\mathrm{a}}$ & $1,60^{\mathrm{a}}$ & $1,86^{\mathrm{c}}$ & $1,78^{\mathrm{bc}}$ \\
\hline Probabilidades & NS & NS & 0,01 & 0,0001 & 0,001 & 0,01 \\
\hline Probabilities & \multicolumn{6}{|c|}{$\begin{array}{c}\text { Contrastes - Probabilidades } \\
\text { Contrasts-Probabilities }\end{array}$} \\
\hline $\mathrm{T} 1 \times \mathrm{T} 2$ & NS & NS & 0,07 & 0,01 & NS & 0,01 \\
\hline T7 x T4+T6 & NS & NS & 0,08 & 0,12 & NS & NS \\
\hline $\mathrm{T} 1 \times \mathrm{T} 3+\mathrm{T} 5$ & NS & NS & NS & 0,001 & 0,02 & 0,04 \\
\hline $\mathrm{T} 7 \times \mathrm{T} 3+\mathrm{T} 5$ & NS & NS & 0,11 & 0,001 & 0,003 & 0,01 \\
\hline $\mathrm{T} 7 \times \mathrm{T} 8$ & NS & NS & NS & NS & NS & NS \\
\hline
\end{tabular}

T1:ração farelada, à vontade, $3200 \mathrm{kcal} \mathrm{EM/kg}$.

T2:ração peletizada, restrita em nível de T1, pelete de $4 \mathrm{~mm}, 3200 \mathrm{kcal}$ EM/kg

T3+T5: ração peletizada, à vontade, 2 e $4 \mathrm{~mm}, 2900 \mathrm{kcal} \mathrm{EM} / \mathrm{kg}$.

T4+T6: ração peletizada, restrita ao nível de T1, 2 e $4 \mathrm{~mm}, 2900 \mathrm{kcal} E M / \mathrm{kg}$.

T7: ração farelada, à vontade, $2900 \mathrm{kcalEM} / \mathrm{kg}$.

T8: ração farelada, restrita em nível de T1, $2900 \mathrm{kcal} E M / \mathrm{kg}$.

T1:meshed diet, ad libitum, $3200 \mathrm{kcal} \mathrm{ME} / \mathrm{kg}$.

T2:pelleted diet, pair-feed at T1 level, pellet with $4 \mathrm{~mm}, 3200 \mathrm{kcal} \mathrm{ME} / \mathrm{kg}$.

T3:pelleted diet, ad libitum, pellets with 2 and $4 \mathrm{~mm}, 2900 \mathrm{kcal} \mathrm{ME} / \mathrm{kg}$.

T4:pelleted diet, pair-feed at T1 level, 2 and $4 \mathrm{~mm}, 2900 \mathrm{kcal} \mathrm{ME} / \mathrm{kg}$.

T7:meshed diet, ad libitum, $2900 \mathrm{kcal}$ ME/kg.

T8:meshed diet, pair-fed at T1 level, 2900kcalME/kg.

Rev. bras. zootec., 30(6S):2026-2032, 2001 
Ad libitum (T1-AE/Ad/RF x T7-BE/Ad/RF), observa-se que as recebendo baixa energia não foram eficientes em ajustar o consumo de acordo com o nível energético. Apesar de no T7 ter havido maior consumo em gramas de alimento, o consumo energético foi menor. No entanto, ambos os tratamentos tiveram a mesma eficiência calórica.

A mortalidade total durante o período experimental foi de 3,51\%. A peletização foi responsável por $79,6 \%$ da mortalidade, o que pode ser explicado pela maior taxa de crescimento das aves com dietas peletizadas, decorrente de maior consumo de alimento, assim como foi verificado por BARBOSA e CAMPOS (1995). Não foi observada influência do nível energético da dieta sobre a mortalidade das aves $(8,3$ e $10,8 \%$ para os tratamentos com 3200 e $2900 \mathrm{EM}$ $\mathrm{kcal} / \mathrm{kg}$, respectivamente), independente da forma física empregada, o que também está de acordo com os dados encontrados por BARBOSA e CAMPOS (1995) e LECZNIESKI (1997).

\section{Conclusões}

O principal efeito da peletização é facilitar para as aves a apreensão do alimento, acarretando aumento de consumo alimentar. Quando há imposição de restrição alimentar, o desempenho torna-se semelhante ao observado com rações fareladas. A equalização de consumo em dietas peletizadas e fareladas com baixa energia mostrou que parece haver um efeito "extra calórico" produzido pela peletização que não é observado nas dietas com alta energia, além do aumento de consumo per se.

Aves alimentadas com rações peletizadas de baixa energia, oferecidas à vontade, tiveram melhor desempenho e maior retorno econômico do que as aves alimentadas com rações fareladas em ambos os níveis energéticos. Tamanho de pelete ( 2 e $4 \mathrm{~mm})$ não influenciou desempenho e rendimento de carcaça das aves.

\section{Referências Bibliográficas}

BARBOSA, M.J.B., CAMPOS, E.J. 1995.Incidência de ascite de acordo com níveis de energia metabolizável e forma física de rações em frangos de corte criados com separação de sexo. Arq. Bras. Med. Vet. Zootec., 47:397-405.

BERTECHINI, A.G., ROSTAGNO, H.S., FONSECA, J.B. et al. 1991.Efeitos da forma física e níveis de energia da ração sobre o desempenho e carcaças de frangos de corte. R. Soc. Bras. Zootec., 20:229-240.
CALET, C. 1965.The relative value of pellets versus mash and grain in poultry nutrition. W. Poult. Sci. J., 21:23-52.

FEED MILLING HANDBOOK. 1980. Coop. extension service, Mississipi: CES. p.100.

GOTTSCHALDT , K.M., LAUSMANN, S. 1974. The Peripheral morphological basis of tactile sensibility in the beak of gease. Cell and Tissue Research, 153:477-496.

GUIDONI, A.L. Alternativas para comparar tratamentos envolvendo o desempenho nutricional animal. Piracicaba, 1994. 105p. Tese (Doutorado em Agronomia - Zootecnia) - Escola Superior de Agricultura Luiz de Queiroz, Piracicaba, 1994.

JENSEN, L.S., MERRIL, L.H., REDDY, C.V. 1962. Observations on eating patterns and rate of food passage of birds fed pelleted and unpelleted diets. Poult. Sci., 41:1414-1419.

KLEIN, C.H. Efeito da forma física e do nivel de energia da ração sobre o desempenho, a composição de carcaça e a eficiência de utilização da energia metabolizável consumida por frangos de corte.1996. 118f. Dissertação (Mestrado em Agronomia - Zootecnia) - Programa de Pós-Graduação em Agronomia, Universidade Federal do Rio Grande do Sul, Porto Alegre, 1996.

LECZNIESKI, J. L. Efeito da forma física e do nivel de energia da ração sobre o desempenho, a composição de carcaça, a utilização e a retenção da energia líquida de frangos de corte, machos, dos 21 aos 42 dias de idade, 1997. 108f. Dissertação (Mestrado em Agronomia - Zootecnia) - Programa de PósGraduação em Agronomia, Universidade Federal do Rio Grande do Sul, Porto Alegre, 1997.

LEVEILLE, A. 1972. Lipogenic adaptations related to pattern of food intake. Nutr. Rev., 7:151-155.

MAIORKA, A. Efeito da forma física, nivel de energia em dietas formuladas com base em aminoácidos totais e digestiveis no desempenho e composição de carcaças de frangos de corte, machos, dos 21 aos 42 dias de idade, 1998. 115p. Dissertação (Mestrado em Zootecnia) - Universidade Federal do Rio Grande do Sul, Porto Alegre, 1998.

NILIPOUR, A, 1994.Produciendo pelets de calidad. Ind. Avícola, 41:28-30.

NIR, I., TWINA, Y., GROSSMAN, E. et al. 1994.Quantitative effects of pelleting on performance gastrointestinal tract and behaviour of meat-type chickens. Brit. Poult. Sci., 35:589-602.

PFOST, H.E., HEADLEY,V. 1976. Methods of determining and expressing particle size. In: FEED MANUFACTURING TECHNOLOGY, 1976, Arlington. Animal Feed Manufactoring Association. Appendix C. Am.

SCHULTZ, R. The progressive animal feed production and its fundamentals. 1990.Adv. Feed Tech., 3:6-33.

SKINNER, J.T., WALDROUP, A.L., WALDROUP, P.W. 1992.Effects of dietary nutrient density on performance and carcass quality of broilers 42 to 49 days of age. J. Appl. Poult. Res., 1:367-372.

SLINGER, S. J. Effect of pelleting and crumbling methods on the nutritional values of feeds. In: EFFECT OF PROCESSING ON THE NUTRITIONAL VALUE OF FEEDS, 1972, Gainesville. Proceedings... Gainesville: Limerick, 1972. p.48-66.

SU, G., SORENSEN, P., KESTIN, S.C. 1999. Meal feeding is more effective than early feed restriction at reducing the prevalence of leg weakness in broiler chickens. Poult. Sci., 78:949-955.

YU, M.W., ROBINSON, F.E. 1992. Restriction to broiler chicken production: a review. J. Appl. Poult. Res., 1:147-153.

Recebido em: 27/09/00 Aceito em: 07/05/01

Rev. bras. zootec., 30(6S):2026-2032, 2001 